\title{
Using the Online Edition
}

The University of Texas Libraries, together with the University of Texas Press, has launched a complete online version of the print edition of the Ballads of the Lords of New Spain at www.utdigital.org. The website reproduces the Nahuatl text and English translation as printed here, but with "pop-up" excerpts from the Commentary to allow the songs and the explanatory synopses to be read together. Extra features include a normative transcription (searchable), a map showing the "geography" of the Ballads, audio of the two-tone drum cadences accompanying two of the songs, and a photographic facsimile of the Ballads codex.

In addition - and with a nod to the expanding field of corpus linguistics - the Ballads website amplifies the "whole corpus" approach to translating and interpreting both the Ballads and the closely related codex Cantares Mexicanos by mounting a single-word extract from the Ballads/Cantares concordance that demonstrates the unity of the diction. To facilitate the interpretation of the Ballads, the website includes the Cantares Mexicanos: Songs of the Aztecs and A Nahuatl-English Dictionary and Concordance to the Cantares Mexicanos, courtesy of Stanford University Press.

A word of thanks is due E. Casey Kittrell at the University of Texas Press for conceiving the Ballads website and guiding it to completion, and to the University of Texas Libraries and its Nettie Lee Benson Latin American Collection for co-sponsoring the project. 
THIS PAGE INTENTIONALLY LEFT BLANK 
Ballads of the Lords of New Spain 
THIS PAGE INTENTIONALLY LEFT BLANK 